ACCEPTED MANUSCRIPT

\title{
Screen-printed and spray coated graphene-based RFID transponders
}

To cite this article before publication: Kaarle Jaakkola et al 2019 2D Mater. in press https://doi.org/10.1088/2053-1583/ab48d8

\section{Manuscript version: Accepted Manuscript}

Accepted Manuscript is "the version of the article accepted for publication including all changes made as a result of the peer review process, and which may also include the addition to the article by IOP Publishing of a header, an article ID, a cover sheet and/or an 'Accepted Manuscript' watermark, but excluding any other editing, typesetting or other changes made by IOP Publishing and/or its licensors"

This Accepted Manuscript is @ 2019 IOP Publishing Ltd.

During the embargo period (the 12 month period from the publication of the Version of Record of this article), the Accepted Manuscript is fully protected by copyright and cannot be reused or reposted elsewhere.

As the Version of Record of this article is going to be / has been published on a subscription basis, this Accepted Manuscript is available for reuse under a CC BY-NC-ND 3.0 licence after the 12 month embargo period.

After the embargo period, everyone is permitted to use copy and redistribute this article for non-commercial purposes only, provided that they adhere to all the terms of the licence https://creativecommons.org/licences/by-nc-nd/3.0

Although reasonable endeavours have been taken to obtain all necessary permissions from third parties to include their copyrighted content within this article, their full citation and copyright line may not be present in this Accepted Manuscript version. Before using any content from this article, please refer to the Version of Record on IOPscience once published for full citation and copyright details, as permissions will likely be required. All third party content is fully copyright protected, unless specifically stated otherwise in the figure caption in the Version of Record.

View the article online for updates and enhancements. 
Radio frequency identification (RFID) is a ubiquitous technology[1], with applications in access control[1], contactless payment[2], electronic passports[1], supply chain management[3], healthcare[4], food packaging[5] and animal identification[6]. It is also the cornerstone of the so-called "Internet of Things" (IoT) [7], where people and devices are seamlessly integrated in a decentralized common set of resources, creating a convergence of the physical realm with human-made virtual environments[8]. Within IoT, every "thing" is connected[8], and the already widespread RFID technology is likely to become even more ubiquitous, combining additional functionalities such as sensing $[9,10]$ and energy harvesting $[11,12]$.

The basic elements of a typical RFID system are tags[1] and readers[1], exchanging information via radio waves[1]. Tags comprise integrated circuits containing a memory to store the tag identity (ID) and the reading/writing circuitry[1]. Tags communicate with the reader via a suitable antenna, which typically has the double role of drawing energy from the reader to run the integrated circuit[1], and exchange data with the reader[1]. RFID offers advantages over other identification technologies, such as barcodes[1], since an RF tag does not need to be in sight of the reader and can, therefore, be embedded in objects[1]. Also, RFID allows simultaneous reading of several tags[1], making the identification process very fast, typically a few $\mathrm{ms}$ for passive (i.e. powered by the reader through the antenna) tags[1] and even shorter for active ones (i.e. battery powered) [1].

RFID tags should combine mechanical robustness (e.g. to tolerate vibrations) [1], light weight (typically $<10 \mathrm{~g}$ ) [1], compact dimensions $(\sim \mathrm{cm})[1]$, reliability[1] and low $\operatorname{cost}(<0.05 \$)[13]$. Mechanical flexibility might also be required (especially for IoT[14]), adding specific challenges not present on rigid systems, such as shifts in resonant frequency[14], and return loss (i.e. reflected power loss caused by antenna input impedance mismatch)[14] and changes in effective capacitance (i.e. the ratio of change in charge to corresponding change in potential)[14], radiation pattern distortion[14] and gain degradation[14]. Different operational scenarios also introduce additional complexity, e.g. proximity to tissues in wearables[14].

Large volume (several millions of units)[13] and low cost $(<0.05 \$$ per unit)[13] manufacturability is essential, as it is expected that over one trillion IoT devices will be deployed by $2025[15,16]$. The most common tags, consisting of a planar electric dipole antenna[17-19], are fabricated from a metallized plastic foil by acidic etching $[1]$. However, this process results in metal waste[20], which is also environmentally harmful[20].

Printing is a promising alternative[14], as it combines high volume production (e.g. an industrial screen printer can print areas $>3 \mathrm{~m} \times 6 \mathrm{~m}$ in a single pass[21]) and, at the same time, avoids chemical etching and material wastage. $\mathrm{Ag}$ inks are typically used for printed RFID[22, 23], since they have high conductivity $\sim 10^{6} \mathrm{~S} / \mathrm{m}[24]$. However, the $\mathrm{Ag}$ cost is very high $(\sim 800-1000 \$ / \mathrm{kg})[25]$. Printed $\mathrm{Ag}$ films have limited flexibility, breaking at $\sim 75 \%$ strain[26] and resistance increase up to $15 \%$ upon bending [26].

Printed graphene layers can be an alternative to printed metals[27] as graphene combines good conductivity[27] and mechanical robustness[27]. Graphene can be dispersed in solvents (such as NMP[28] or water[28]), doped[28] or functionalized[28]. The surface resistivity of single layer graphene (SLG) at radio $(300 \mathrm{KHz}$ to $300 \mathrm{MHz})$ and microwave $(300 \mathrm{MHz}$ to $300 \mathrm{GHz}$ ) frequencies is higher than metals[29], resulting in losses[29] that prevent its use in antennas with high (>90\%) efficiency (i.e. ratio between power irradiated by the antenna and power supplied)[29]. The SLG conductivity can be tuned by field effect[30]. However, the changes are mostly in the real part[29], while in the imaginary part these are small up to $100 \mathrm{GHz}[31,32]$, resulting in limited reconfigurability (i.e. tunability of radiation frequency, pattern or polarization)[33] .

Thick $(>1 \mu \mathrm{m})$ exfoliated graphite films, consisting of 
few-layer graphene (FLG) flakes, can overcome such limitations, showing sheet resistances $\mathrm{R}_{S}<2 \Omega / \square[34]$, corresponding to conductivities $>10^{4} \mathrm{~S} / \mathrm{m}[34]$. These can also be deposited over large $\left(\mathrm{m}^{2}\right)$ areas by screen printing or spray coating.

Screen printing is a common industrial technique for roll-to-roll patterned deposition[21]. Typical formulations of screen inks contain a conductive filler, such as Ag particles[26], and insulating additives (e.g. stabilizers and binders)[39], at a total concentration $>100 \mathrm{~g} / \mathrm{L}[39]$. Of this, $>60 \mathrm{~g} / \mathrm{L}$ consists of the conductive filler needed to achieve sufficiently high $\left(>10^{6} \mathrm{~S} / \mathrm{m}\right)$ conductivities[26, 40]. Spray coating is also suitable for roll-to-roll production[41]. To the best of our knowledge, there are no reports on spray coated graphene-based antennas. However, spray coated FLG films with similar specifications to those needed for RFID antennas $\left(\mathrm{R}_{S} \sim 6 \Omega / \square\right.$ and thickness $\sim 8 \mu \mathrm{m}$ ) were reported for use in Electromagnetic Interference (EMI) shielding[42].

A number of antennas based on solution-processed FLG films were reported[43-48]. Their reduced performance in gain and radiation efficiency compared to metallic antennas (typically over one order of magnitude[33]) is compensated by other functionalities, such as mechanical flexibility[48]. RFID transponders, based on FLG film antennas combined with RFID integrated circuits, were demonstrated[44, 45, 48], showing typical reading distance up to $9 \mathrm{~m}[47]$. This is smaller than commercial RFIDs, providing $>10 \mathrm{~m}[44,45,48]$.

The input impedance of a typical RFID microchip at operating frequencies $(865-868 \mathrm{MHz}$ in Europe and $915 \mathrm{MHz}$ in US[1]) is capacitive[1, 51], with a real part lower than the absolute value of the reactance[1, 51]. Thus, to match the impedance conjugately, i.e. to ensure that both microchip and antenna are electrically compatible with each other, the impedance of the antenna should be the complex conjugate to that of the microchip at the frequency of operation[22]. A two-branch dipole antenna might not have such a point on its impedance curve because of design[50], dimensions[50] or materials used[50]. The conjugate impedance match between microchip and antenna can be achieved by forming a loop inductor parallel to the feeding point on the antenna conductor[19].

Conductivity of printed graphene is lower than $\mathrm{Al}$ or Ag inks. Thus, even if the lower conductivity is taken into account in the design of the transponders, they still have shorter reading distance than commercial ones.

Here, we present a wideband RFID transponder with a hybrid Al-printed graphene antenna with reading distance competitive with commercial ones. Our transponders consist of graphitic antennas either screen printed on Kapton or sprayed on paper, coupled with a RFID chip through Al inductive loops, ensuring impedance matching, i.e. that the impedance of the antenna is the complex conjugate impedance of the microchip at the frequency of operation. The Al loop is significantly smaller than the overall antennas size, therefore minimizing use of metal and not compromising the flexibility of the overall transponder. These have reading distances up to $11 \mathrm{~m}$ in the relevant UHF RFID bands: 865.6-867.6MHz (Europe) and 902-928 MHz (USA and Japan), larger than graphene-based RFID tag previously reported [44, 45, 47, 48] and comparable with commercial RFID transponders[49].

\section{ANTENNA DESIGN}

The antennas are designed using the electromagnetic simulation software High Frequency Structure Simulator (HFSS) 15 (Ansys Inc. USA), assuming $\mathrm{R}_{S} \sim$ $3 \Omega / \square$, as typical for dried FLG films produced by microfluidizaton[34]. The two main parameters of a transponder antenna are input impedance[1], to match the antenna with the transponder microchip, and radiation efficiency, defined as the ratio of power radiated by the antenna and power supplied[50].

We use an Impinj Monza R6 UHF RFID microchip, with a 96 bits memory. This employs unregulated codes and is compatible with a wide range of tag form factors[51]. The input impedance is 16 -j139 $\Omega$ at $915 \mathrm{MHz}[51]$. This is prevalently capacitive, with a real part lower than the absolute value of the reactance. Thus, to match the impedances conjugately, the antenna should have an impedance $\mathrm{Z}_{\text {ant }}=16+\mathrm{j} 139 \Omega$ at the same frequency, i.e. it should be sufficiently inductive with a low real part of the impedance. In order to achieve this, a parallel inductor in the dipole antenna is implemented as a opening on the conductor[44, 48].

We also introduce a hybrid structure in which we combine the printed FLG antenna with an $\mathrm{Al}$ inductive loop for impedance matching. The Al loop is significantly smaller than the overall size of the transponder, therefore minimizes the use of metals and does not compromise flexibility. The loop forms inductive coupling between microchip and antenna FLG conductor. Thus, no direct connection of microchip to FLG film is required.

We design and simulate FLG antennas using both FLG inductors and $\mathrm{Al}$ inductive loops. Both designs are made for the same FLG $\mathrm{R}_{S} \sim 3 \Omega / \square$. The optimized outer dimensions of the antenna to work at $915 \mathrm{MHz}$ with the FLG inductive loop, shown in Fig. 1, are $114 \mathrm{~mm} \times 34 \mathrm{~mm}$ and the dimensions of the opening are $13.3 \mathrm{~mm} \times 10.1 \mathrm{~mm}$. The outer dimensions of the hybrid antenna, Fig.2, are the same. The dimensions of the upper opening of the antenna are $18.3 \mathrm{~mm} \times 6 \mathrm{~mm}$, and those of the lower opening are $18.3 \mathrm{~mm} \times 20 \mathrm{~mm}$.

The main tunable parameters of the antennas, optimized by simulations, are the circumference of the loop and the length of the antenna. The first determines the input reactance of the antenna[44, 48], while the latter determines the radiation resistance, i.e. the resis- 
1

2

3

4

5

6

7

8

9

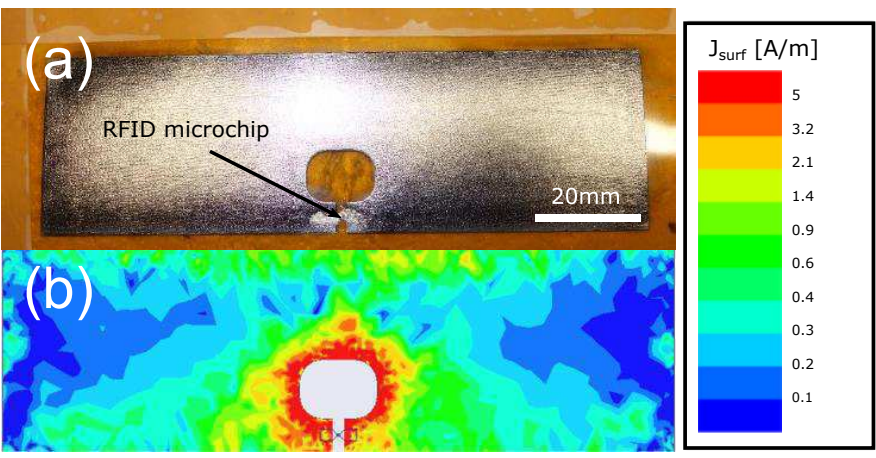

FIG. 1. a)Antenna with FLG inductor. b) Simulated current distribution. $\mathrm{J}_{\text {surf }}$ is the surface current density in $\mathrm{A} / \mathrm{m}$

\begin{tabular}{|l|l|l|l|l|}
\hline Material & $\begin{array}{l}\text { thickness } \\
(\mu \mathrm{m})\end{array}$ & $\mathrm{e}_{r} @ 915 \mathrm{MHz}$ & $\tan (\mathrm{d}) @ 915 \mathrm{MHz}$ & \\
\hline PEN & 125 & 2.6 & 0.01 & $\begin{array}{l}\text { this } \\
\text { work }\end{array}$ \\
\hline PET & 50 & 2.8 & 0.01 & $\begin{array}{l}\text { this } \\
\text { work }\end{array}$ \\
\hline $\begin{array}{l}\text { fine } \\
\text { paper }\end{array}$ & 120 & 4 & 0.125 & {$[52]$} \\
\hline
\end{tabular}

TABLE I. Dielectric materials used in simulations

tance caused by the radiation of electromagnetic waves from the antenna[53]. In the hybrid antenna, a rectangular opening is added, rather than a loop, to minimize Eddy currents induced by the inductive loop, since these would increase losses and decrease radiation efficiency. Shape and dimensions of the opening are chosen to minimize Eddy currents without significantly affecting antenna conductivity. The inductive loop, with $14 \mathrm{~mm} \times 6 \mathrm{~mm}$ outer dimensions, is made of $0.8 \mathrm{~mm}$ wide and $9 \mu \mathrm{m}$ thick Al, Fig.2. Simulations consider the FLG $\mathrm{R}_{S}$ as uniform. The dielectric substrates are included in the simulation. Under the FLG antenna, there is a layer of dielectric. The hybrid antenna is simulated using two substrates: $125 \mu \mathrm{m}$ thick PEN and $120 \mu \mathrm{m}$ thick fine paper. In the hybrid antenna, there is also a $50 \mu \mathrm{m}$ thick PET as a carrier layer between FLG and Al. The parameters of the dielectric layers are listed in Table I and are obtained by measurement using a HP 4291A impedance analyzer with a HP16453A dielectric material test fixture or from Ref.[52]. The adhesive tape used to attach the $\mathrm{Al}$ loop into the antenna is not included in the final model as its effect on the antenna parameters is negligible. The antenna is not sensitive to the dielectric properties of the adhesive tape on the top of the loop. This is due to the operation of the loop as an inductor, in which the magnetic field dominates over the electric field.

Table II summarizes the simulated parameters at 915MHz: input impedance $\mathrm{Z}_{\text {ant }}$, attenuation due to impedance mismatch $\mathrm{L}_{Z}$, radiation efficiency $\eta$, directivity (i.e. rátio between maximum radiation intensity in the main beam and average radiation intensity over

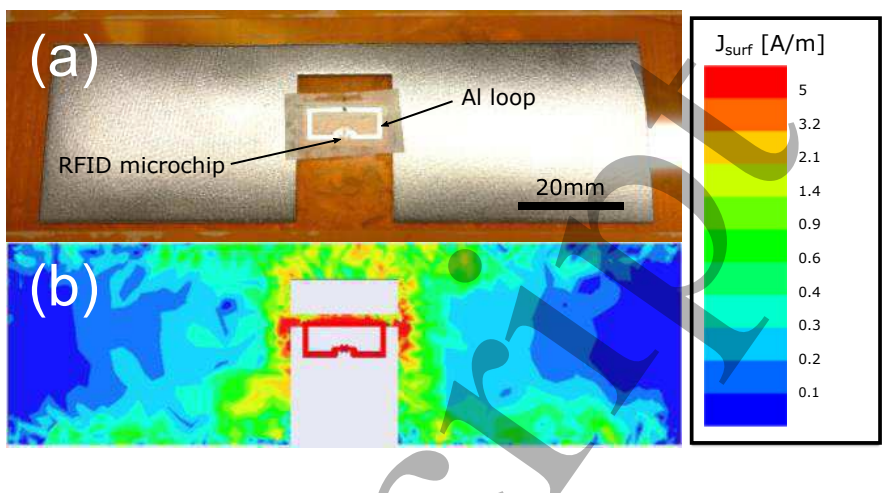

FIG. 2. (a) Hybrid antenna with metal inductor. The larger structure is the printed FLG, while the inner loop is the $\mathrm{Al}$ inductor. b) Simulated current distribution. $\mathrm{J}_{\text {surf }}$ is the surface current density in $\mathrm{A} / \mathrm{m}$.

\begin{tabular}{|l|l|l|l|l|l|}
\hline Transponder & $\mathrm{Z}_{\text {ant }}(\mathrm{Ohms})$ & $\begin{array}{l}\mathrm{L}_{Z} \\
(\mathrm{~dB})\end{array}$ & $\begin{array}{l}\eta \\
(\mathrm{dB})\end{array}$ & $\begin{array}{l}\mathrm{D}_{\text {tag }} \\
(\mathrm{dB})\end{array}$ & $\begin{array}{l}\mathrm{R}_{\text {read }} \\
(\mathrm{m})\end{array}$ \\
\hline $\begin{array}{l}\text { Antenna with FLG } \\
\text { inductive loop on } \\
\text { PEN }\end{array}$ & $77.5+\mathrm{j} 138$ & -2.3 & -5.4 & 3.2 & 8.9 \\
\hline $\begin{array}{l}\text { Hybrid antenna on } \\
\text { PEN }\end{array}$ & $17.2+\mathrm{j} 136$ & 0 & -4 & 3 & 13.1 \\
\hline $\begin{array}{l}\text { Hybrid antenna on } \\
\text { paper }\end{array}$ & $17.9+\mathrm{j} 137$ & 0 & -4.1 & 3 & 13 \\
\hline
\end{tabular}

TABLE II. Simulated parameters of the tag antennas at $915 \mathrm{MHz}$

all space) $\mathrm{D}_{t a g}$ and calculated read range, i.e the calculated maximum distance that the RFID tag can be read, $\mathrm{R}_{\text {read }}$. As shown by Table II, the impedance of the antenna is not affected by the substrate materials, and the antenna dimensions remain the same between different substrates. The attenuation due to the impedance mismatch between antenna and microchip is calculated from the impedances as[50]:

$$
L_{Z}=1-\left|\left(Z_{a n t}-Z_{I C}^{*}\right) /\left(Z_{a n t}+Z_{I C}\right)\right|^{2}
$$

where $\mathrm{Z}_{I C}$ is the complex impedance of the microchip. The forward-link (i.e. from reader to tag[54]) read range is calculated as [54, 55]:

$$
R_{\text {read }}=(c / 4 \pi f) \times\left(P_{\text {txEIRP }} D_{\text {tag }} \eta_{\text {tag }} L_{Z} / P_{\text {ICsens }}\right)^{1 / 2}
$$

where $\mathrm{c}$ is the speed of light, $\mathrm{f}$ is the frequency, $\mathrm{P}_{t x E I R P}$ is the equivalent isotropically radiated power (i.e. measured radiated power in a single direction) of the reader device and $\mathrm{P}_{\text {ICsens }}$ is the read sensitivity of the microchip (i.e. minimum power required to activate the chip). $\mathrm{P}_{t x E I R P}=3.28 \mathrm{~W}$ is the maximum allowed radiated power of a UHF RFID reader as defined by the European regulatory environment for radio equipment and spectrum [56]. $\mathrm{P}_{\text {ICsens }}=-20 \mathrm{dBm}$, as specified for the Impinj Monza R6 microchip by the manufacturer[51]. Table II indicates that the transponder with a hybrid antenna 
has a longer read range $(13.1 \mathrm{~m})$. This is due to both better impedance match between antenna and microchip, and higher radiation efficiency.

\section{EXPERIMENTAL}

Based on the design optimized by simulations, FLG antennas are fabricated either by screen printing or spray coating.

Inks suitable for screen printing and spray coating are formulated by adding different amounts of rheology modifiers after exfoliation of graphite to tune the ink viscosity. Graphite flakes (Timrex KS25) are added to deionized (DI) water at a concentration $100 \mathrm{~g} / \mathrm{L}$ and sodium deoxycholate $(\sim 5 \mathrm{~g} / \mathrm{L})$. The mixture is processed using a microfluidizer (M-110P) at $207 \mathrm{MPa}$ for $70 \mathrm{cy}-$ cles. One cycle is defined as one pass of the liquid mixture through the interaction chamber, where high shear rate $\left(\sim 10^{8} \mathrm{~s}^{-1}\right)$ is applied[34]. The exfoliated graphite flakes have a lateral size distribution peaked at $1 \mu \mathrm{m}$ and thickness $\sim 12 \mathrm{~nm}[34]$. Microfluidization is a homogenization technique whereby high pressure (up to $207 \mathrm{MPa}$ ) is applied to a fluid[35], forcing it to pass through a microchannel (diameter $<100 \mu \mathrm{m})$. Other liquid phase exfoliation processes, such as sonication and shear-mixing, have low yields $(<2 \%[36-38])$ since shear forces are not applied uniformly[38]. The key advantage of microfluidization is that high shear is applied to the whole fluid volume[34], not just locally, subjecting all the material to intense shear forces.

Fig.3 plots a representative Raman spectrum, acquired by a Renishaw inVia at $514 \mathrm{~nm}$ excitation, of the processed material after microfluidization. The 2D peak consists of two components $\left(2 \mathrm{D}_{2}, 2 \mathrm{D}_{1}\right)$. Their intensity ratio changes from $\sim 1.5$ for the starting graphite to 1.2 , indicating exfoliation, but not complete to SLG 34,57$]$.

Following microfluidization, carboxymethylcellulose (CMC) sodium salt is added at a concentration $\sim 10 \mathrm{~g} / \mathrm{L}$ to prepare a screen printable (SP) ink and $\sim 5 \mathrm{~g} / \mathrm{L}$ for the spray coatable (SC) one. CMC acts as rheology modifier giving the SP-ink a viscosity ranging from $\sim 570 \mathrm{mPa}$ $\mathrm{s}$ at $100 \mathrm{~s}^{-1}$ to $140 \mathrm{mPa} \mathrm{s}$ at $1000 \mathrm{~s}^{-1}$, and to the $\mathrm{SC}$ one $220 \mathrm{mPA}$ s at $100 \mathrm{~s}^{-1}$ to $60 \mathrm{mPa}$ s at $1000 \mathrm{~s}^{-1}$.

The SP-ink is used to form FLG films both for antennas with FLG inductor and hybrid antennas on Kapton using a screen printer (Kippax KPX-2012) equipped with a 90 mesh per inch screen. These are then annealed at $265^{\circ} \mathrm{C}$ for 10 minutes to remove the binder and increase conductivity, $\mathrm{R}_{S}$ of the printed antennas measured using a four-point probe is $\sim 5 \Omega / \square$, reduced to $\sim 3 \Omega / \square$ after annealing at $265^{\circ} \mathrm{C}$ for 10 mins. Fig.4a is a scanning electron microscope (SEM) image of the printed film after annealing. Annealing at higher temperatures or for longer times further reduces $\mathrm{R}_{S}$, however it causes delamination from Kapton, making the antenna not usable.

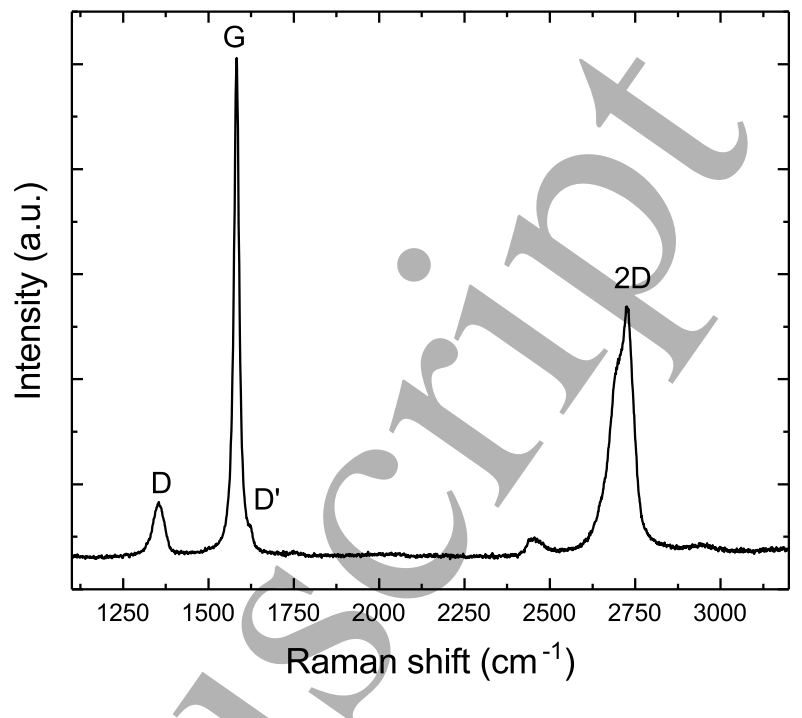

FIG. 3. Representative Raman spectrum at $514 \mathrm{~nm}$ for flakes processed for 70 cycles.
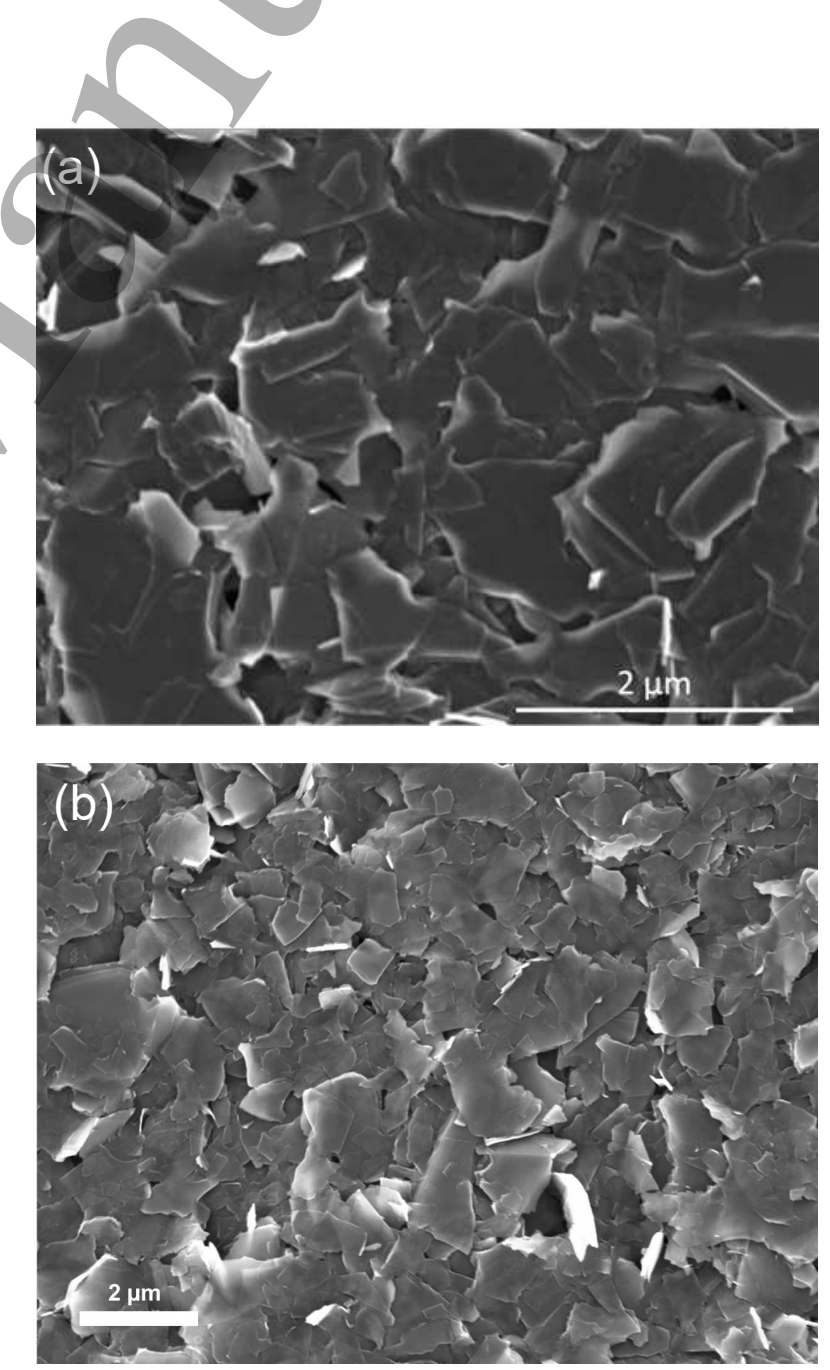

FIG. 4. SEM images of a)SP film on Kapton; b) SC film on paper 
The SC-ink is used for hybrid antennas and sprayed onto 3 substrates: 1) Polyethylene Naphthalate (PEN), Q65HA-125 $\mu \mathrm{m} ; 2$ ) multicoated matt art paper (Lumisilk$120 \mu \mathrm{m})$; 3) uncoated printing paper (Tesorp). The substrate is cut into the shape of the simulated antenna. SC is performed using a hand held manual spray pen for $\sim 5 \mathrm{~s}$, while moving over the antenna area, so that ink covers the whole substrate, resulting in a self-standing antenna. Air pressure is kept constant and the spraying distance is $\sim 20 \mathrm{~cm}$. The dry thickness of one pass is $15-18 \mu \mathrm{m}$. A SEM image of a FLG film on paper is in Fig.4b.

The uncoated paper completely absorbs the water from the ink and the samples are dried and flattened using a hot press at $130{ }^{\circ} \mathrm{C}$. The samples are then calendered using a cylinder press with one steel roller and one hard rubber roller, generating a pressure $\sim 80 \mathrm{bar}(\sim 36 \mathrm{kN} / \mathrm{m})$. The compression is performed at $2 \mathrm{~m} / \mathrm{min}$ and up to 3 times. The adhesion of the dry ink on plastic and multicoated paper is not optimal, so this process is only done for uncoated printing paper, where the ink is more easily absorbed deep into the substrate. $\mathrm{R}_{S}$ is measured by four-probe close to the centre of the antenna, where the highest conductivity is required, as shown in the simulations in Figs.1,2. $\mathrm{R}_{S}$ saturates at $\sim 3.6 \Omega / \square$ after 2 spray passes. Further calendaring or additional coating do not further reduce $\mathrm{R}_{S}$. The reason is that paper fibres limit the conducting pathways available for the FLG flakes, as the ink is absorbed into the substrate before it can dry, due to the FLG concentration and the evaporation of water. SEM images of SP films on Kapton and SC on paper are shown in Figs.4a,b.

For the transponder with FLG inductor, the microchip is glued directly to the antenna using $\mathrm{Ag}$ paste. For the hybrid system, the Al inductive loop is fabricated similarly to conventional dipole transponders[1], i.e. by etching $\mathrm{Al}$ on polyethylene terephthalate (PET)[1]. The microchip is subsequently attached onto the Al loop using anisotropic conducting adhesive (ACA) [58] and the loop is attached on the antenna with adhesive tape.

The benefits of using a separate metal loop with an inductive coupling to the antenna radiator are based on using high conductivity metal (such as $\mathrm{Al}$ or $\mathrm{Cu}$, with $\mathrm{R}_{S} \sim 3 \mathrm{mOhm} / \square$ ) as the loop material (as the current density is highest in the loop), which makes the loop conductor narrow $(\sim 0.8 \mathrm{~mm})$, and the loop small $(\sim 14 \mathrm{~mm} \times 6 \mathrm{~mm})$. The microchip is then easy to attach with existing industrial processes[59, 60]. Due to low loss in the metal loop, the efficiency of the antenna is higher. The loop is significantly smaller than the overall antenna size, minimizing use of metal, not compromising the flexibility of the transponder. Using an Al inductor loop not only improves impedance matching in terms of conjugate impedance, but also reduces signal attenuation between antenna and microchip. Indeed, forming a contact between FLG antennas and microchip is challenging, especially considering the small $(\sim 400 \mu \mathrm{m} \times 250 \mu \mathrm{m})$ contact

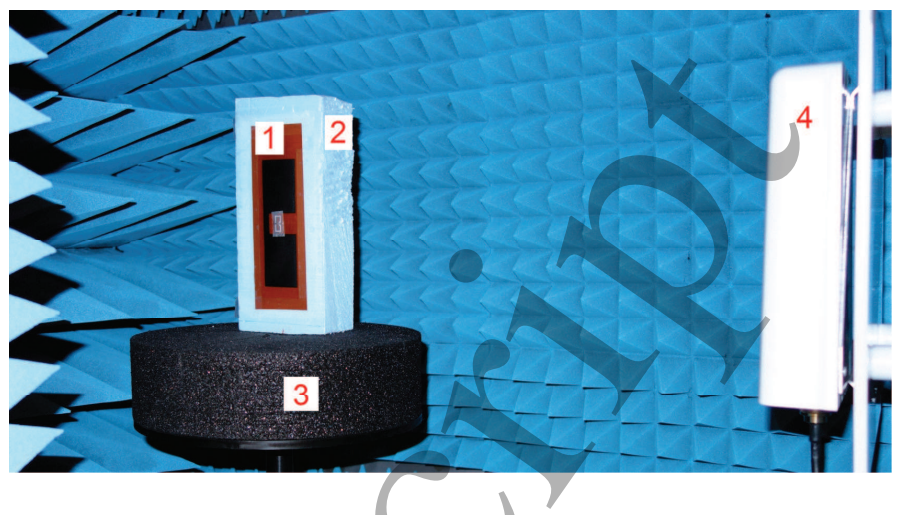

FIG. 5. Measurement setup of the transponder. The transponder under test (1) is taped on a piece of styrofoam (2) that is placed on a turntable (3). The measurement antenna (4) is connected to the tagformance device. The distance between (1) and (4) is $500 \mathrm{~mm}$

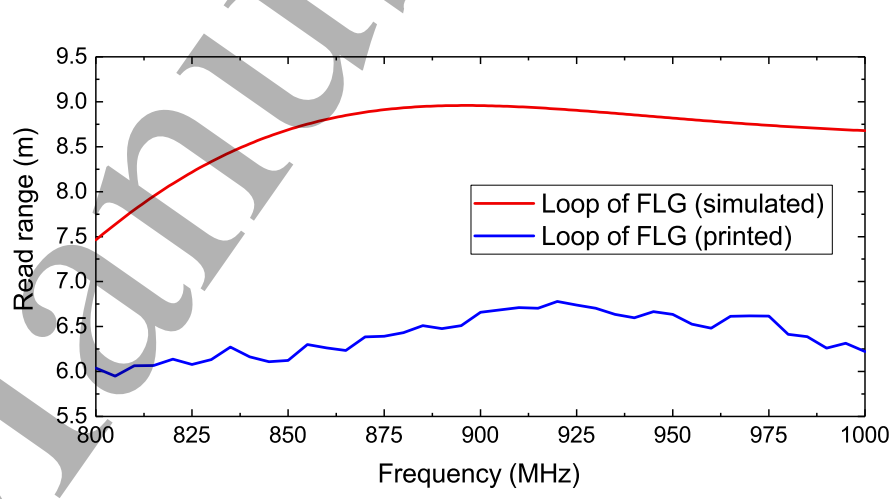

FIG. 6. Simulated and measured read range as a function of frequency for antenna with FLG inductive loop on PET

pads of an RFID microchip. ACA, typically used with metallic tags[58], does not necessarily work on FLG, due to the temperature and pressure required by the bonding process[61]. Therefore, similar to Ref.[62], for the antenna with FLG inductive loop we use Ag paint to establish an electrical contact between FLG films and RFID chip, Fig.1a. Conversely, in our hybrid design, the printed FLG antenna and the RFID chip are con-

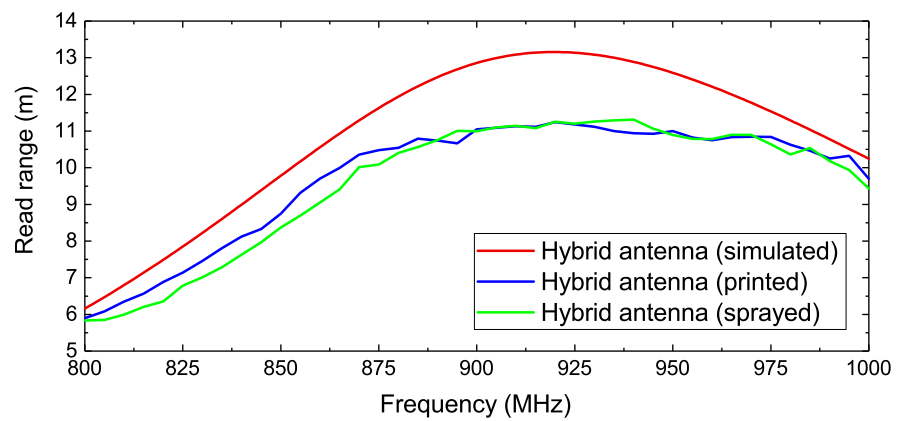

FIG. 7. Simulated and measured read range as a function of frequency for hybrid antenna on PET 

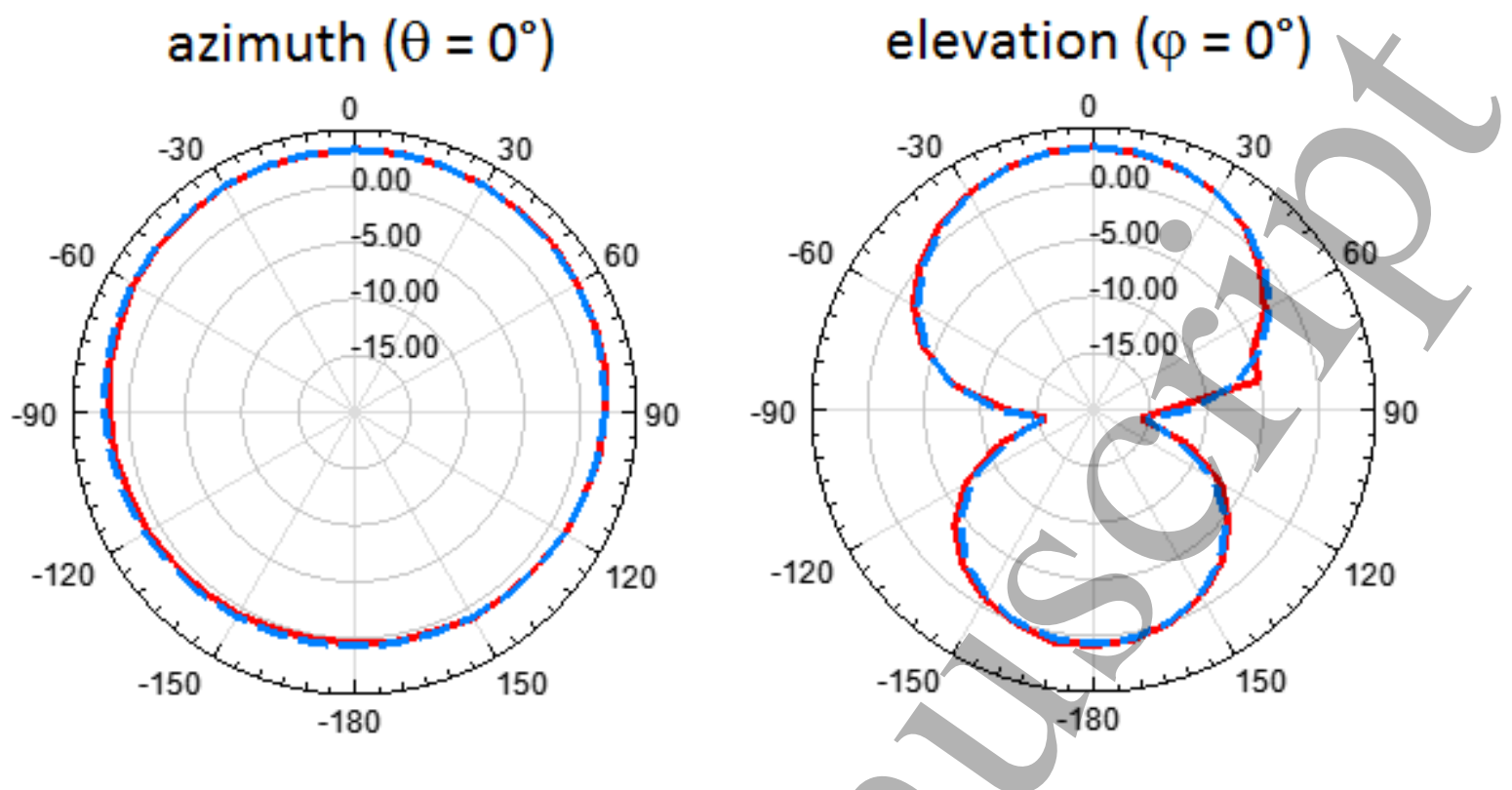

FIG. 8. Measured (solid line) and simulated (dashed line) directivity of antenna with FLG inductive loop on PET in azimuth and elevation plane

\section{azimuth $\left(\theta=0^{\circ}\right)$ \\ elevation $\left(\varphi=0^{\circ}\right)$}
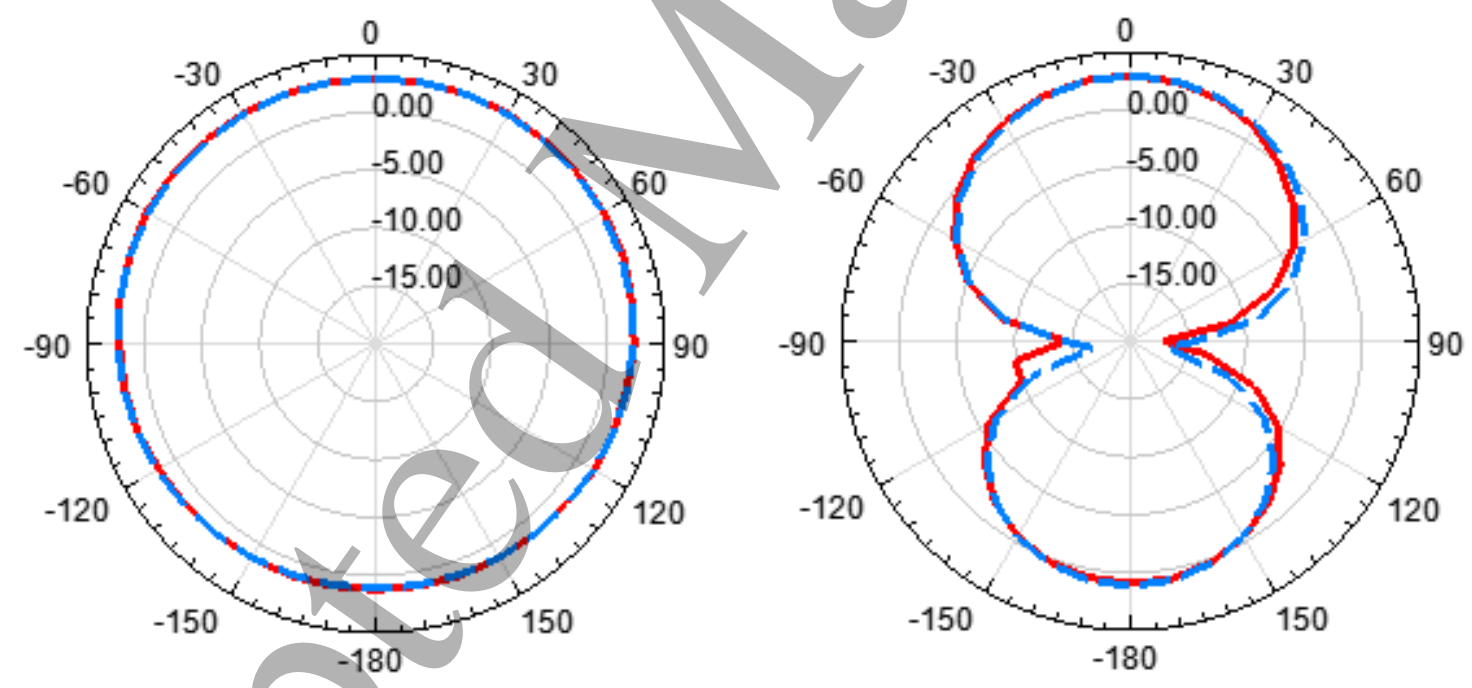

FIG. 9. Measured (solid line) and simulated (dashed line) directivity of hybrid antenna on PET in azimuth and elevation plane

nected through the Al loop and no bonding or Ag paint is required between loop and FLG antenna. Therefore, conventional ACA can be used to bond the RFID chip to the $\mathrm{Al}$ loop.

\section{RESULTS AND DISCUSSIONS}

Fig.1 shows image and simulated current distribution of the antenna with parallel inductor implemented as an opening on the FLG conductor. The current is concentrated around the opening or the loop inductor of the transponder, Fig.1b. The hybrid antenna is shown in Fig.2a. Fig.2b is the corresponding simulated current distribution. The highest density of current is in the metal conductor, thus maximizing power transfer to the microchip, therefore improving the reading range.

The measurement setup of the transponder is shown in Fig.5. The antennas are measured with a Tagformance $^{\mathrm{TM}}$ UHF RFID measurement system[63] in 
its anechoic cabinet. The evaluation is based on measuring the activation level of the transponder in a fixed and known setup[54, 64]. The transponders are attached on a piece of Styrofoam, acting as radiation-transparent support. The measured activation level is then used to calculate the theoretical reading range (i.e. the maximum range) in Figs.6,7. The simulated reading ranges are also included for comparison.

For all antennas, the measured read range is shorter than simulations. However, for the hybrid antenna the discrepancy is smaller. A possible cause for this is the roughness of the edges in the $\mathrm{SP}$ antennas. Fig.1 indicates that the current concentrates on the edges of the opening or the loop in the middle. Thus any added resistivity there has a significant impact on losses. This also explains why the difference between simulations and measurements is greater for antennas with FLG inductive loop. These also use Ag paste as the conductor between antenna and microchip. The connections between Ag paste and FLG, as well as between Ag paste and microchip contact pads, are likely to introduce additional contact resistance, hence signal attenuation. The contact resistance between the microchip pads and FLG, and the roughness of the loop inner edge, are the main reasons for the difference between simulations and experiments. The impact of the contact resistance was studied in Ref.[65]. The roughness of the loop inner edge is apparent by inspection using a microscope, but it is difficult to model electromagnetically. As the RF current concentrates on this inner loop edge, the effect on losses may be large.

Fig. 7 shows that the reading range of SP and SC antennas are almost identical. Only below $\sim 880 \mathrm{MHz}$ the distance of SP antennas is $10 \%$ smaller than SC, showing how both deposition methods are suitable for the realization of FLG antennas.

The radiation patterns are also measured with the Tagformance $^{\mathrm{TM}}$ system. Figs.8,9 compare measured directivities (solid red lines) and simulations (dashed blue lines). As the absolute directivity is difficult to measure, the measured radiation patters are normalized to the simulated ones at $\phi=0, \theta=0$.

Radiation patterns, both simulated and measured, reveal a small difference compared to an ideal dipole antenna. The radiation pattern is not perfectly round on the azimuth plane. The difference in directivity between 0 and $180^{\circ}$ is $2.8 \mathrm{~dB}$ for the FLG inductive loop antenna and $1.7 \mathrm{~dB}$ for the hybrid one. This can also be seen on the elevation plane. The maximum directivity in Table 1 is above the theoretical one of a dipole antenna, $2.15 \mathrm{dBi}$ (decibels relative to isotropic radiator) [50]. This can be attributed to the asymmetry of the transponders combined with the FLG $\mathrm{R}_{S}$.

\section{CONCLUSIONS}

UHF RFID transponders with screen-printed and sprayed FLG antennas were designed, fabricated and tested. Read ranges 6.7 and $11.1 \mathrm{~m}$ were measured for antennas with FLG inductive loop and hybrid antennas, respectively. The transponders operate at the frequency bands reserved for UHF RFID: 865.6-867.6 MHz (Europe) and 902-928 MHz (USA, Japan). The hybrid antenna has reading performance superior to previously reported graphene-based RFID tags $[44,45,47,48]$ and comparable with commercial ones[49]. It also avoids the need for a direct contact between FLG film and microchip, making the fabrication of FLG antennas compatible with existing industrial processes.

\section{ACKNOWLEDGEMENTS}

We acknowledge funding from EU Graphene Flagship, the French RENATECH network, ERC Grants Hetero2D and MINERGRACE, EPSRC Grants EP/K01711X/1,

EP/K017144/1, EP/N010345/1, and EP/L016087/1.

[1] K. Finkenzeller, RFID Handbook: Radio-Frequency Identification Fundamentals and Applications (Wiley, New York, 2004) 2nd ed.

[2] I. Lacmanovi, B. Radulovia, D. Lacmanovi, Contactless Payment Systems Based on RFID Technology (The 33rd International Convention MIPRO, Opatija, 2010) 1114.

[3] A. Musa, A. Dabo, Global J. Flexible Syst. Manage. 17, 189 (2016).

[4] S. Fosso Wamba, A. Anand, and L. Carter, Int. J. Inf. Manage. 33, 875 (2013).

[5] K. B. Biji, C. N. Ravishankar, C. O. Mohan, and T. K. S. Gopal, J. Food Sci. Tech. Mys. 52, 6125 (2015).

[6] R. Geers, B. Puers, V. Goedseels, and P. Wouters, Electronic identification, monitoring and tracking of animals (CAB INTERNATIONAL, Wallingford, 1997).

[7] K. Ashton, RFID Journal, (2009).

[8] R. Buyya and A. V. Dastjerdi, Internet of things principles and paradigms, (Elsevier, 2016).

[9] R. Nair, E. Perret, S. Tedjini, and T. Barron, A humidity sensor for passive chipless RFID applications (RFID-TA, Nice, 2012) 29-33.

[10] S. Manzari, S. Pettinari, and G. Marrocco, Miniaturized and tunable wearable RFID tag for body-centric applications (RFID-TA, Nice, 2012) 239-243.

[11] A. N. Parks and J. R. Smith, Sifting through the airwaves: Efficient and scalable multiband RF harvesting (IEEE RFID, Orlando, 2014) 74-81.

[12] R. M. Ferdous, A. W. Reza, and M. F. Siddiqui, Renew. Sust. Energ. Rev. 58, 1114 (2016).

[13] G. Swamy and S. Sarma, Manufacturing Cost Simulations for Low Cost RFID, Auto-ID Center, MIT, 2003.

[14] H. Kaleel, Innovation in Wearable and Flexible Antennas (WIT Press, Southampton, 2015). 
[15] J. Manyika, R. Dobbs, M. Chui, J. Bughin, P. Bisson, and J. Woetzel, The IoT: mapping the value beyond the hype, McKinsey Global Institute, 2015.

[16] M. Romagnoli, V. Sorianello, M. Midrio, F. H. L. Koppens, C. Huyghebaert, D. Neumaier, P. Galli, W. Templ, A. D'Errico, A. C. Ferrari; Nature Rev. Mater. 3, 392 (2018)

[17] K. V. S. Rao, P. V. Nikitin, and S. F. Lam, IEEE T. Antenn. Propag. 53, 3870 (2005).

[18] G. Marrocco, IEEE Antenn. Propag. M. 50, 66 (2008).

[19] K. Finkenzeller, RFID Handbook: Fundamentals and Applications in Contactless Smart Cards, Radio Frequency Identification and near-Field Communication (Wiley, 2010).

[20] Z. Cui, Printed Electronics: Materials, Technologies and Applications (John Wiley \& Sons Singapore Pte. Ltd, Singapore, 2016).

[21] https://www.hgkippax.co.uk.

[22] P. V. Nikitin, S. Lam, and K. V. S. Rao, Low cost silver ink RFID tag antennas (IEEE Antennas and Propagation Society International Symposium, Washington, 2005) 2B, 353.

[23] P. Pongpaibool, A study of cost-effective conductive ink for inkjet-printed RFID application (International Symposium on Antennas and Propagation (ISAP), Nagoys, 2012) $1248-1251$.

[24] A. L. Dearden, P.J. Smith, D.Y. Shin, N. Reis, B. Derby, and P. OBrien, Macromol. Rapid Commun. 26, 315 (2005).

[25] A. Louwen, W. van Sark, R. Schropp, and A. Faaij, Sol. Energ. Mat. Sol. C 147, 295-314 (2016).

[26] S. Merilampi, T. Laine-Ma, and P. Ruuskanen, Microelectron. Reliab. 49, 782 (2009).

[27] A.C. Ferrari, et al., Nanoscale 7, 4598-4810 (2015).

[28] F. Bonaccorso, A. Lombardo, T. Hasan, Z. Sun, L. Colombo, and A. C.Ferrari, Mater. Today 15, 564-589 (2012).

[29] J. Perruisseau-Carrier, Graphene for antenna applications: Opportunities and challenges from microwaves to $\mathrm{THz}$ (Loughborough Antennas \& Propagation Conference (Lapc), Loughborough, 2012).

[30] K.S. Novoselov, A.K. Geim, S.V. Morozov, D. Jiang, Y. Zhang, S.V. Dubonos, G. IV, and A.A. Firsov, Science 306, 666-669 (2004).

[31] S.A. Awan, A. Lombardo, A. Colli, G. Privitera, T.S. Kulmala, J.M. Kivioja, M. Koshino, and A.C. Ferrari, 2D Mater. 3, 015010 (2016).

[32] J. Horng, C.F. Chen, B.S. Geng, C. Girit, Y.B. Zhang, Z. Hao, H.A. Bechtel, M. Martin, A. Zettl, M.F. Crommie, Y.R. Shen, and F. Wang, Phys. Rev. B 83, 165113 (2011).

[33] J. Perruisseau-Carrier, M. Tamagnone, J. S. GomezDiaz, and E. Carrasco, Graphene antennas: Can integration and reconfigurability compensate for the loss (European Microwave Conference (EuMC), Nuremberg, 2013) 369-372.

[34] P. G. Karagiannidis, et al., ACS Nano 11, 2742 (2017)

[35] T. Panagiotou, S.V. Mesite, J.M. Bernard, K.J. Chomistek, R.J. Fisher. NSTI-Nanotech 1, 688 (2008)

[36] T.Hasan,F. Torrisi, Z. Sun, D. Popa, V. Nicolosi, G. Privitera, F. Bonaccorso, A.C. Ferrari, Phys. Status Solidi B 247, 2953 (2010)

[37] F. Torrisi, T. Hasan, W. Wu, Z. Sun, A. Lombardo, T.S. Kulmala, G.W. Hsieh, S. Jung, F. Bonaccorso, P.J. Paul,
D. Chu, A.C. Ferrari, ACS Nano 6, 2992 (2012).

[38] K. R. Paton, E. Varrla, C. Backes, R.J. Smith, U. Khan, A. O'Neill, C. Boland, M. Lotya, O.M. Istrate, P. King, T. Higgins, S. Barwich, P. May, P. Puczkarski, I. Ahmed, M. Moebius, H. Pettersson, E. Long, J. Coelho, S.E. O'Brien, et al. Nat. Mater. 13, 624 (2014)

[39] J. W. Birkenshaw, The Printing Ink Manual, R. H. Leach, R. J. Pierce, E. P. Hickman, M. J. Mackenzie, and H. G. Smith (Springer, Dordrecht, 2007) 5th ed. 2, $14-85$.

[40] W. J. Hyun, S. Lim, B. Y. Ahn, J. A. Lewis, C. D. Frisbie, and L. F. Francis, ACS Appl. Mater. \& Interfaces 7, 12619 (2015).

[41] A. Moridi, S.M. Hassani-Gangaraj, M. Guagliano, and M. Dao, Surf. Eng. 30, 369 (2014).

[42] C. Acquarelli, A. Rinaldi, A. Tamburrano, G. D. Bellis, A. G. D. Aloia, and M. S. Sarto, Graphene-based EMI shield obtained via spray deposition technique (International Symposium on Electromagnetic Compatibility, Gothenburg, 2014) 488-493.

[43] X. J. Huang, T. Leng, X. Zhang, J. C. Chen, K. H. Chang, A. K. Geim, K. S. Novoselov, and Z. R. Hu, Appl. Phys. Lett. 106, 203105 (2015).

[44] M. Akbari, M. W. A. Khan, M. Hasani, T. Bjorninen, L. Sydanheimo, and L. Ukkonen, IEEE Antennas Wirel. Propag. Lett. 15, 1569 (2016).

[45] P. Kopyt, B. Salski, M. Olszewska-Placha, D. Janczak, M. Sloma, T. Kurkus, M. Jakubowska, and W. Gwarek, IEEE T. Antenn. Propag. 64, 2862 (2016).

[46] A. Lamminen, K. Arapov, G. de With, S. Haque, H. G. O. Sandberg, H. Friedrich, and V. Ermolov, IEEE Antennas Wirel. Propag. Lett. 16, 1883 (2017).

[47] K.W. Pan, Y.Y. Fan, T. Leng, J.S. Li, Z.Y. Xin, J.W. Zhang, L. Hao, J. Gallop, K.S. Novoselov, and Z.R. Hu, Nat. Commun. 9, 5197 (2018).

[48] K. Arapov, K. Jaakkola, V. Ermolov, G. Bex, E. Rubingh, S. Haque, H. Sandberg, R. Abbel, G. de With, H. Friedrich, Physica Status Solidi 10, 812 (2016)

[49] https://www.smartrac-group.com/files/content/Products_ Services/PDF/0028 _ SMARTRAC _ DOGBONE.pdf.

[50] D. M. Pozar, Microwave Engineering (Wiley, New York, 2011).

[51] Impinj Monza R6 ${ }^{\mathrm{TM}}$ UHF RFID microchip, datasheet. https://support.impinj.com/hc/enus/articles/202765328-Monza-R6-Product-Datasheet.

[52] K. P. Vepsalainen, H. Seppa, T. Varpula, J. Pulp and Paper Science 24188 (1998).

[53] T. A. Milligan, Modern Antenna Design (McGraw Hill, New York, 1985).

[54] P. Nikitin, K. V. S. Rao, and S. Lam, UHF RFID tag characterization: Overview and state-of-the-art (Antenna measurement techniques association symposium (AMTA), Seattle, 2012).

[55] Z. Su, S. C Cheung, K. T. Chu, Investigation of radio link budget for UHF RFID systems, In Proc. 2010 IEEE International Conference on RFID-Technology and Applications, (Guangzhou, 2010)

[56] The European regulatory environment for radio equipment and spectrum, https://cept.org/ (2017).

[57] A. C. Ferrari, J. C. Meyer, V. Scardaci, C. Casiraghi, M. Lazzeri, F. Mauri, S. Piscanec, D. Jiang, K. S. Novoselov, S. Roth et al., Phys. Rev. Lett. 97, 187401 (2006).

[58] Y.C. Lin, J. Zhong, J. Mater. Sci. 43, 3072 (2008). 
[59] H. Chu, B. An, F. Wu, Y. Wu, Proc. 7th Int. Conf. Electron. Packag. Technol. Aug. 2006

[60] J. S. Rasul, Microelectron. Rel. 44, 135 (2004)

[61] J. Liu, ACA bonding technology for low cost electronics packaging applications-current status and remaining challenges (4th Int. Conf. on Adhesive Joining and Coating Tech. in Electronics Manufacturing, 2000).
[62] X. Huang, et al., Sci. Rep. 5, 18298 (2015).

[63] http://www.voyantic.com.

[64] P. Pursula, M. Hirvonen, K. Jaakkola, and T. Varpula, IEEE T. Antenn. Propag. 55, 2836 (2007).

[65] K. Jaakkola, H. Sandberg, M. Lahti, V. Ermolov, IEEE Trans. on Components, Packaging and Manufacturing Technology, 9, 616 (2019)

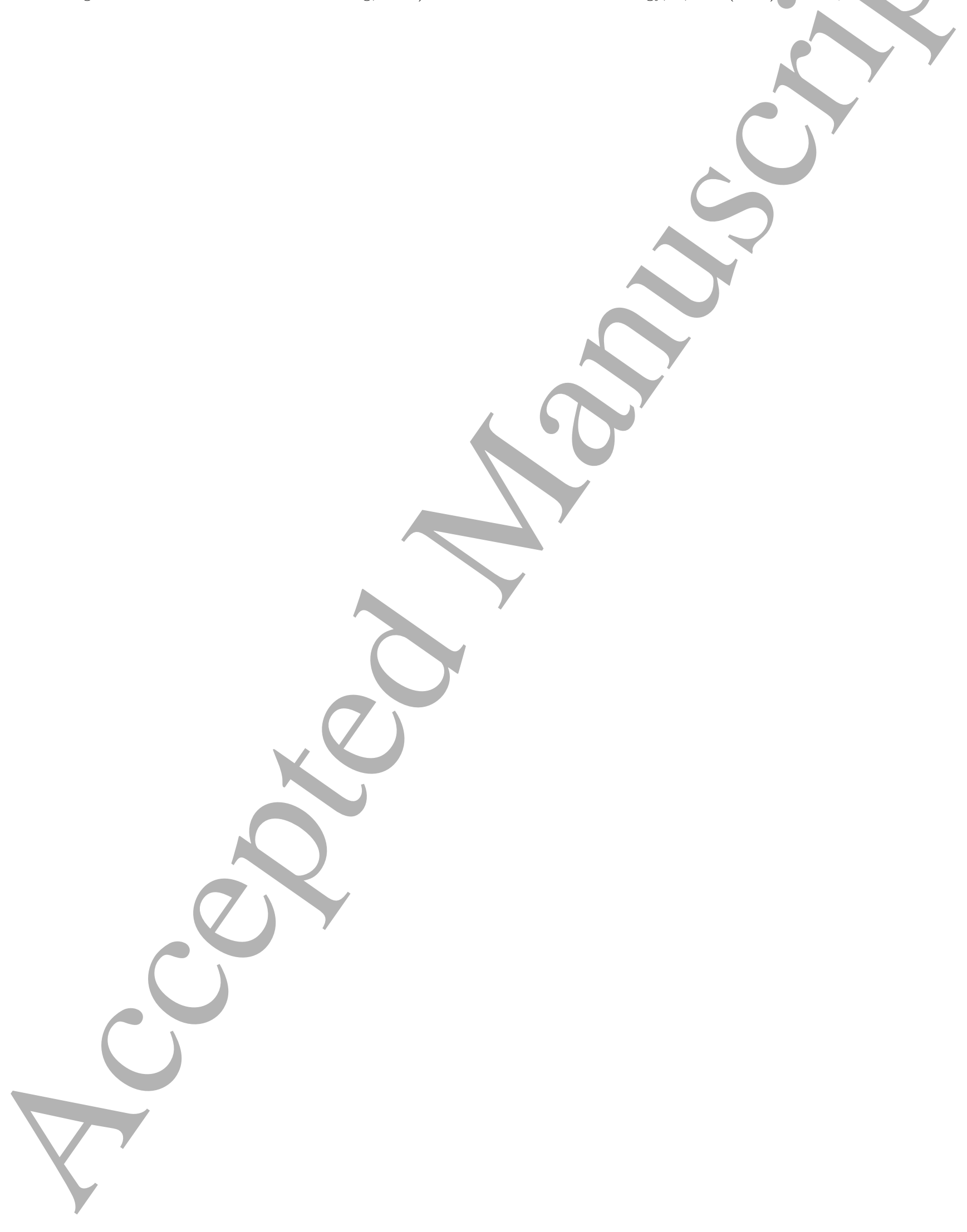

